of such work in the bigger picture of a country's health system. The paramount objective of volunteer work should be to support and strengthen a local weak or insufficient healthcare system so that all urgent health needs can be appropriately addressed at all times.

Dr Coleman himself provides some excellent examples of the errors and dangers of the traditional paradigm of dental volunteering. He describes his own experiences of "taking oral health promotion material and dietary sheets, tubes of toothpaste and thousands of toothbrushes only to see them traded for cash five minutes later to buy food'. It continues to surprise us that volunteers and their organisations continue to ship toothpaste, toothbrushes and other dental equipment halfway round the world, no doubt at great expense both financially and environmentally, with little consideration of the appropriateness or sustainability of this approach. What happens when these imported goods have been used up or, in this case, traded for food? Is it not better to resource materials locally, for instance negotiate for more affordable toothpaste with local Kenyan toothpaste suppliers $^{3}$ and to recommend the use of the traditional toothbrush, the musuake or meswak, which Dr Coleman himself describes in one of his previous letters to the editor of the BDJ. ${ }^{4}$ Furthermore, what is the sense of using dietary advice sheets where the local people are seemingly so poor that they need to trade their donated toothbrushes and toothpaste for food?

Dr Coleman also cites the example of a Moran warrior who, as a result of severe toothache, had a tooth extracted by a friend that resulted in the warrior's eventual death. Dr Coleman uses this story as a justification for his engagement in Kenya, a country, where the dentist to population ratio is only 1:150,000 5 and where he was able to extract a huge number of diseased teeth. It is a pity that this incident did not lead to deeper reflection and eventual realisation that the traditional dental volunteering paradigm, as practised by Dr Coleman himself, which largely consists of short-term visits mostly to extract teeth, will contribute very little to prevent such deadly incidents from happening again. Nor for that matter will it prevent the possible spread of serious infections such as hepatitis and HIV when teeth are extracted by untrained local traditional healers or quacks. ${ }^{6}$ Who will address dental emergencies if volunteers like Dr Coleman are not around? The FDI World Dental Federation clearly stated that 'emergency care and service provision are important aspects of volunteer activities. However, ensuring the long-term impact and sustainability of activities should be equally important, i.e. by training local personnel, introducing preventive measures or similar activities." It is in this context that in our paper we analysed the traditional volunteer approach critically and concluded that it may actually be more of a hindrance than a help.

Dr Coleman queries our credentials asking whether we 'have ever run a dental clinic in a third world country'. We can reassure him that collectively, not only have we delivered direct handson oral healthcare in regions as far apart as Asia, the Indian subcontinent, Africa and Latin America, but we have experience of oral healthcare systems in several dozens of low-and middleincome countries. It is a result of this broad experience that we have had the opportunity to reflect on the activities of dental volunteers and propose more effective and perhaps more ethical models for volunteer engagement to improve oral health.

The enormous rift that appears to exist between the traditional paradigm of dental volunteers and a more comprehensive development model that has repeatedly been proposed ${ }^{8}$ highlights the urgent need for constructive dialogue between the different actors, volunteers included, based on the common desire of improving oral and general health for those who suffer from poverty. ${ }^{9}$ As Dickson and Dickson ${ }^{10}$ stated, 'there is a strong need to change our thinking about what constitutes assistance. We must shift from a charity model of dental aid to poor countries to one that involves helping local efforts to extend primary care and address the causes of poor oral health. For that to happen, we need to think and act outside the box, to view and practise dentistry aimed at improving population health.' This process is not easy, but inevitable and overdue. Otherwise preventable oral diseases will continue to take their toll on populations and eventually kill, not only in 'third world countries', but also in our rich contexts. ${ }^{11}$

1. Snyder J, Dharamsi S, Crooks VA. Fly-By medical care: Conceptualizing the global and local social responsibilities of medical tourists and physician voluntourists. Global Health 2011;7: 6.

2. Shapka A. Letter to the editor. J Can Dent Assoc 2006; 72: 194

3. Euromonitor International. Oral care in Kenya. August 2011. (accessed October 2011). Available from: http://www.euromonitor.com/oral-care-inkenya/report

4. Coleman R O. Antibacterial twig. Br Dent J 2011; 211: 4.

5. Beaglehole R, Benzian H, Crail J, Mackay J. The oral health atlas: mapping a neglected global health issue. Geneva \& Brighton: FDI World Dental Education Ltd \& Myriad Editions, 2009.

6. Wanaswa Z. Community Health Information Centers and the Traditional Healers in Maasai Land. WIRED International-Kenya (accessed October

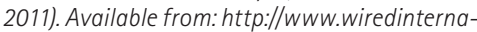
tional.org/kenya/kenya_traditionalHealersMaasaiLand.html

7. FDI World Dental Federation. Guidelines for dental volunteers. FDI Policy Statement, Montréal. 2005. (accessed October 2011). Available from: http://tiny. cc/qwtnk

8. HM Government. Health is global: a UK government strategy 2008-13. London: Department of Health, 2008.

9. Hobdell M H. Poverty, oral health and human development: contemporary issues affecting the provision of primary oral health care. J Am Dent Assoc 2007: 138: 1433-1436.

10. Dickson M, Dickson G. Volunteering: beyond an act of charity. J Can Dent Assoc 2005; 71: 865-869.

11. American Dental Association. American Dental Association Statement on the death of Deamonte Driver. 2 March 2007. (accessed October 2011). Available from: http://tiny.cc/h02v4

DOI: 10.1038/sj.bdj.2011.971

\section{OCULOMOTOR CONCERN}

Sir, I was just admiring the artwork on the front of Volume 211 No. 6 featuring the abducens nerve supplying the lateral rectus muscle. My concern is that, in the illustration, the oculomotor nerve has branches supplying all the other extraocular muscles including the superior oblique muscle. This muscle actually takes its motor supply from the trochlear nerve, or 4th cranial nerve as shown correctly in Volume 211 No. 4.

R. F. K. Rutland Thatcham DOI: 10.1038/sj.bdj.2011.972 